\title{
The Social and Psychological Characteristic of a Victim of Sexual Violence
}

\author{
Alla Albertovna Semerikova ${ }^{1}$, Sergey Alexandrovich Kokotov ${ }^{2}$, Valentina Romanovna Bugrova ${ }^{3} \&$ Victor \\ Mihailovich Novgorodtsev ${ }^{1}$ \\ ${ }^{1}$ Russian State University of Tourism and Service, Legal Disciplines, Jurisprudence, Russian Federation \\ ${ }^{2}$ Russian State University of Tourism and Service, Faculty of Economics, Management and Law, Historical \\ Sciences, Russian Federation \\ ${ }^{3}$ Russian State University of Tourism and Service, Legal Disciplines, Philosophy, Russian Federation \\ Correspondence: Alla Albertovna Semerikova, Glavnaya St., 99, Cherkizovo village, 141221, Pushkinsky district, \\ Moscow region, Russian Federation. Tel: 49-5-940-8360. E-mail: alla-semerikova@yandex.ru
}

Received: November 10, $2014 \quad$ Accepted: December 14, $2014 \quad$ Online Published: March 20, 2015
$\begin{aligned} & \text { doi:10.5539/ass.v11n8p264 } \\ & \text { URL: http://dx.doi.org/10.5539/ass.v11n8p264 }\end{aligned}$

\begin{abstract}
The article studies the nature of behavior of a victim of criminal violence; describes the social and psychological portrait of a potential victim of violent sexual actions; reveals the reasons of high victimity of a victim; analyzes the essence of behavior of a victim under the influence of the processes of expectation and socialization and their direct interaction; evaluates the influence of congenital and acquired mental abnormalities on the behavior of a victim of sexual violence, particularly, studies the incidences of disorders of sexual preference and other deviations from normal sexual behavior typical of the modern society.
\end{abstract}

Keywords: victim, victimity, sexual violence, mental deviations, motivation, instinct, demand, mental abnormalities, disorders of sexual preference, latency

\section{Main Part}

The personality of a victim is traditionally not considered by criminologists. Nevertheless, its role in commitment of violent offenses of sexual nature is extremely essential. Criminologists consider that personality is the carrier of reasons of crime commitment. certainly; first of all, it concerns the person guilty in commitment of a socially dangerous act. However, one should not underestimate the role of the victim in formation of sexual motivation, as well. It is sexual violence that is associated with the closest ties between the criminal and the victim.

Sexual violence inherently is the kind of criminal aggression connected, first of all, with socialization defects of the personality of both the criminal and the victim; with in-depth processes of degradation developing under the influence of destructive social processes or as a result of forming or existing mental abnormalities and mental disturbances, especially disorders of sexual preference and sexual identification.

The personality of a victim as well as the personality of a criminal is formed in the course of socialization, which is understood as "assignment of public properties to a person, the choice of the life journey, establishment of social ties ... and acquisition of certain social roles and functions". I.e. the society assigns certain social role status to the individual. Under the influence of society, the person chooses the way of his further development, sets socially significant purposes to himself, chooses acceptable ways of achievement of the specified purposes. The moral principles of behavior are formed with the individual, and the question of admissibility and legitimacy of certain affirmations and behavior variants is solved.

The very essence of behavior depends not only on the socialization process, but also on such phenomenon as expectation, which we understand as a system of expectations and requirements to standards of social roles performance by an individual - representing a version of social sanctions, which normalize the system of relations and interactions in a group. I.e. the society expects the individual to indicate the model of behavior, which corresponds to the role in the society that he/she has selected. Expectation determines the probabilistic nature of this role performance with account of the specific features of the individual and the particular life situation. In the researched case, it is a gender accessory and historically developed subordinate position of the 
woman or the teenager with respect to the man.

In the system of similar mutual relations, the determining role is played by role circumstances under the influence of socialization, on the one hand, and expectation, on the other hand.

There are three basic models of behavior of a victim:

The consciously provoking behavior - the victim consciously seeks contact with the rapist, whether by sympathy or by trusting him, considering flirtation and joint pastimes acceptable. The game motivation prevails with the victim; she does not deny the possibility of sexual relations or hints at their possibility. As a whole, such victims constituted $25-30 \%$ of the group researched by us. Such victims may be called logical.

The unconsciously provoking behavior - the victim as a result of psychological peculiar features has a slightly deformed understanding about mutual relations between a man and a woman and about difference of the man's mentality from the woman's one. She deems her active or passive actions as neutral, but the man perceives them as inducing to sexual contact. Natural appeal and charm not directed at a particular object, or just natural naivety can be used as an example. Such victims constitute $35-40 \%$.

The neutral behavior is typical of casual victims. The criminal motivation in this case is based on external objective factors, which are in no way connected with conscious or unconscious provocation. Such victims also constitute $30-40 \%$.

Accordingly, we can to use two basic criteria to understand the extent of victimity of a victim: objective and subjective. The objective one are those circumstances, which characterize the reality: economic, political, and social prerequisites, i.e. all that is reflected in reality and does not depend on actions and desires of the individual. The subjective ones include psychological "defects" of the personality, physiological singularities of the personality, and various mental deviancies, starting with insignificant mental abnormalities and ending with disorders of sexual preference.

We questioned 350 persons and interviewed 50 persons of both genders who had become victims of completed sexual violence. As a result of generalization and analysis of the data received during the conducted research, five criteria, characterizing the personality of a victim of sexual violence were identified. The socially demographic, socially professional, and legal criteria, which as a whole constitute the objective criterion, and the morally psychological and medical criteria, which are subjective.

1) The socially demographic criterion, which involves the sex, the age, the educational level, and the marital status.

The majority of victims, namely $-75 \%$ of the interrogated persons, were between 16 and 23 years old; $18 \%$ of the interrogated persons were younger than 16 years old, and only $8 \%$ were found older than 23 years old. As to the educational level, we obtained the following values: higher education - $6 \%$, not completed higher education $9 \%$, not completed secondary education - $18 \%$, specialized secondary education - $32 \%$, not completed specialized secondary education $-19 \%$, and secondary education $-16 \%$ of the interrogated persons. De facto married $-4 \%$, not married/single - $63 \%$, actually married - 33\%, which means that the majority of women, namely $63 \%$, had not been bound with any serious relations at the time of commitment of sexual violence acts against them. Which corresponds to the studies of many Russian criminologists.

2) The socially professional criterion, which includes the social and professional status of the personality.

Persons who have no constant income or low income prevail among the victims of sexual violence. From problem families or pseudo-secured families. For example, $26 \%$ of the interrogated persons had been brought up by their relatives, $6 \%$ had been brought up by foster families, just $15 \%$ had a complete family, $11 \%$ had spent their childhood in an orphan asylum, and $42 \%$ were brought up in incomplete families, $84 \%$ of which had no father. At determination of the professional status, we obtained the following data: $29 \%$ were pupils and students, $4 \%$ - employees, $48 \%$ - had a worker's specialty, and $29 \%$ were unemployed at the time of violence commitment.

When asked "what were your relations in the family?", the majority named absence of mutual understanding $74 \%, 17 \%$ characterized the relations in their families as conflictual, $42 \%$ - as strained, and $72 \%$ of the interrogated persons suffered physical violence.

3) The legal criterion, which can possibly include the legal status of a person in the society, the level of his/her legal awareness and relation to precepts of law.

Quite a low level of legal awareness is typical of them; at that, the following types of deformed legal awareness prevail: legal infancy and legal nihilism. 
Legal infancy is understood as ignorance or insufficient knowledge of laws, indifference to the legal system, underestimation of the law importance. Nevertheless, the person behaves legally, is guided by the example and stereotypes of behavior of other people of the person's social group copying their behavior without reflecting, is not able to protect his/her interests without assistance.

Legal nihilism is described by ignorance of laws, one's rights and mechanisms of their protection, negative attitude to them, illegal behavior, and extremely low esteem of the importance of legal regulation of public relations.

4) The morally psychological criterion, which includes temperament and character singularities, which in combination with moral affirmations determine the model of behavior acceptable for the particular individual.

As to the psychological features of a victim, we revealed an interesting regularity. The personality of the rapist has identical psychological traits with the victim's ones. During the research, we came to this interesting conclusion: each personality has certain character and temperament with the deficiencies, which to some extent are recognized by this person as excessive, hindering further development and harmonious existence. Subconsciously, the person hates these qualities in himself and tries to get rid of them, which provokes discontent with himself, increases the stress, and, consequently, forms the inferiority complex and auto-aggression, i.e. the aggression at himself. Such aggression eventually turns into external aggression and commitment of a socially dangerous act. Accordingly, by means of an act of violence over a victim, the criminal tries to neutralize his own deficiencies and weaknesses, punishing the victim for similar displays of character and temperament.

It turns out that in psychological terms, the victim of sexual violence corresponds to the weak-willed or indifferent type of the violent criminal:

The basic trait of such personality is absence of strong-willed qualities, and this peculiar feature is displayed in all spheres of his/her life: study, work, or the decision-making process. Subconsciously, the personality feels the necessity of submission to a stronger opponent and is exposed to even insignificant pressure. Such traits, as strong suggestibility, passivity, psychological infancy, self-doubt, absence of strongly pronounced strong-willed qualities, hindered decision-making are typical of the person. Representatives of this category are normally indifferent to their own destiny, and their affirmations aim pleasing a stronger person. They virtually never show initiative themselves. They do not have steady interests and devotion.

Inability to resist owing to the psychological principle of non-resistance or the principle of Lucifer, i.e. suppression by a more authoritative personality of the rapist, which is initially perceived as dominating due to the genders of the victim and the rapist. The phenomenon of expectation influences on the victim, too, who psychologically and subconsciously admits the possibility of sexual violence over her, and does not even deny its criminality.

American psychologists described the fear of a victim in the following way: "As fear, hidden semitones of an injurious attack, contact and constraint are the general dominants of violence and decrease of tone immovability as well as in view of that reactions of victims of violence are often identical to the behavior of "hypnotized" animals, we can conclude that the tone immovability and paralysis caused by the fear of the rapist, represent the same phenomenon".

Our studies also confirm the previously mentioned: $85 \%$ could not resist the rapist because of the fear paralyzing them, which is just the base point of formation of the sexual motivation, as rapists enjoy the fear of the victim rather than the sexual intercourse itself.

Table 1. Main psychological traits of victims of sexual violence

\begin{tabular}{lll}
\hline & $\bullet$ envy & $45 \%$ \\
& $\bullet$ estrangement & $62 \%$ \\
& $\bullet$ proneness to submission & 84 \\
& $\bullet$ proneness to auto-violence & $32 \%$ \\
Note, what traits are typical of you: & - proneness to conflicts & 12 \\
& - uncertainty in own safety & $31 \%$ \\
& $\bullet$ emotional stress & $42 \%$ \\
& - uncertainty in your abilities & $93 \%$ \\
& - fear of the future & $94 \%$ \\
& $\bullet$ feeling of uselessness & $72 \%$ \\
\hline
\end{tabular}


Victims of sexual violence identified the following psychological traits with themselves presented in Table 1.

They are described with rather loose views at sexual relations, their sexual views represent an extreme variant of standards, or they are not associated by the majority of the society with the concept of acceptability of this kind of sexual relations, which at the same time are not painful from the medical point of view, i.e. are not of persuasive, obsessive-compulsive nature.

Thus, the "standard of sexual behavior is the sexual behavior, which fits the framework of the contemporary moral ideology based on mutual declaration of will, which behavior is not accompanied by additional stimulation of understanding of the presence of certain items and conditions, in absence of which sexual excitation and sexual satisfaction are impossible".

Table 2. Variants of sexual behavior

\begin{tabular}{lll}
\hline & $\bullet$ I watch sometimes & $43 \%$ \\
Attitude to porno products: & $\bullet$ I watch constantly & $52 \%$ \\
& $\bullet$ I am not interested & $5 \%$ \\
\hline & $\bullet$ yes, it was not pleasant & $2 \%$ \\
Have you ever participated in group sex: & $\bullet$ yes, it was pleasant & $23 \%$ \\
& $\bullet$ no & $1 \%$ \\
& $\bullet$ no, but I would like to & $74 \%$ \\
The relation to the opposite sex: & $\bullet$ I am not interested & $2 \%$ \\
& $\bullet$ I feel constant attraction & $78 \%$ \\
& $\bullet$ I do not feel constant necessity of sexual & $20 \%$ \\
& relations & $26 \%$ \\
Acceptable for you: & $\bullet$ all & $1 \%$ \\
& $\bullet$ only classical sex & $32 \%$ \\
& $\bullet$ anal and genital contacts & $72 \%$ \\
& $\bullet$ role-playing games & $54 \%$ \\
& $\bullet$ role-playing games with BDSM elements & $69 \%$ \\
The attitude to persons of the same sex as you: & $\bullet$ oral and genital contacts & $42 \%$ \\
& $\bullet$ group sex & $2 \%$ \\
\hline Do you have inclinations & $\bullet$ I am confused with such questions & $82 \%$ \\
persuasive nature: & $\bullet$ attracted & $2 \%$ \\
\hline
\end{tabular}

5) The medical criterion, which includes drug and alcohol addiction and various states of mentality including mental abnormalities and mental disorders of any etiology.

The state of alcoholic or narcotic intoxication, which is rather common. More than $30 \%$ of victims of sexual violence were in the state of intoxication. This increased the degree of victimity to a certain extent.

A drunk person loses the ability of fully-fledged self-control, his/her moral and ethical standards lose any value and importance, he/she feels permissiveness, the range of possible behavior models shrinks. Intoxication provokes uncontrolled freedom, aggravates base, animal instincts, desires, which have been suppressed before and forced to the area of the unconscious. Activity of the person starts to be determined by the principle of pleasure.

Thus, according to foreign researchers, $22 \%$ of women at the time of rape were in the state of slight intoxication, $11 \%$ - in the condition of medium alcoholic intoxication, and only $7 \%$ were strongly drunk.

Those victims have a considerably stronger degree of predisposition to victimity who suffer mental deficiency, especially teenagers who have developmental delays compared to their peers.

They correspond to the intellectually limited type. Such persons are initially inclined to perceive the world perversely, cannot comprehensively analyze their actions and actions of other persons, and critically estimate a conflict situation. They face difficulties at perception of new information. The small stock of knowledge, 
concreteness and primitiveness of judgments, criticism infringement, and very weak prognostic abilities etc. contribute to becoming victims of violence.

Masochism is the most widespread disorder of sexual preference of a victim.

Psychologists notice that displays of instincts of sexual submission, sexual surrender can play certain role in the genesis of masochistic tendencies. In these cases, experiencing the feeling of feebleness, humility, and inability to resist moves to the forefront of masochistic experiences. Some feel satisfaction if they are roped, others wish complete submission so that the object of love would offend them, beat, and force to roll at feet. In other cases rough treatment, mobbing, and beating are associated with their representation of the man's power, courage, authoritativeness, due to which masochistic propensity receives positive estimation and develop. The feeling of pain can irradiate causing sexual excitation and voluptuous experiences if the pain is not too severe at that. Masochism is also based on the occurrence of conditionally reflectory relation between the feeling of pain and strong sexual excitation.

Accordingly, persons with masochistic tendencies unconsciously have the precisely formed dream to be an object of violence, humiliation, roughness, mockery, and cruelty displayed by the offender, thus deriving sexual satisfaction from inflicted physical pain or mental violence and experiences associated with them.

Thus, we have received the social and psychological portrait of a victim of sexual violence and revealed those objective and subjective criteria, which add to the increase of the victimity degree.

\section{References}

Antonyan, Y. M. (1993). Chikatilo and Others (pp. 154-162). Moscow: Almateya.

Antonyan, Y. M., Deryagin, G. B., Lebedev, S. Y., \& Eriashvili, N. D. (2011). Criminal Sexology (pp. 222-234). Moscow: "Unity-Dana".

Antonyan, Y. M., Enikeev, M., \& Eminov, V. E. (2004). The Psychology of Crime and Punishment (p. 15). Moscow: Yuridichesky Tsentr Press,.

Antonyan, Y. M., Kudryavtsev, V. N., \& Eminov, V. E. (2004). The Personality of a Criminal (p. 39). Moscow: Yuridichesky TsentrPress.

Freud, S. (1925). Some characters types met with psycho-analytic work. In Collected Papers (Vol. 14, p. 34). London: Hogarth.

Karayani, A. G., \& Tsvetkov, V. L. (2012). Legal Psychology - from Experiment to Practice (p. 12). Moscow: Yunity-Dana.

Pigolkin, Y. I., Dmitrieva, O. A., Shchegin, N. G., \& Deryagin, G. B. (2008). Sexual Violence: Theories, Approaches, and Methods of Research (pp. 222-234). Moscow: "Meditsinskoye Informatsionnoye Agentstvo".

Schwendinger, T., \& Schwendinger, H. (1983). Rape and inequality (p. 240). U.S., Beverly Hills.

Semerikova, A. A. (2012). Paraphilia - the Medical and Criminal Legal Aspect (p. 64). In the Proceedings of the 2012 Scientific and Practical Conference "Contemporary Problems of Development of Social Sciences and Ways of their Solution", Volgograd.

Semerikova, A. A. (2012a). Prevention of Murders by Hooligan Inducement (p. 100). Pyatigorsk: "RIA-KMV".

Semerikova, A. A. (2012b). Prevention of Murders by Hooligan Inducement (p. 102). Pyatigorsk: "RIA-KMV".

Svyadoshch, A. M. (1991). Women's Sexual Pathology (pp. 99-104). Moscow: Shtiintsa.

The Data of anonymous questioning of victims of completed sexual violence, which was carried out in Moscow and the Moscow Region in June-August 2013.

The Data of anonymous questioning of victims of the finished sexual violence, which have been conducted in Moscow and Moscow Region in June-August 2013.

\section{Copyrights}

Copyright for this article is retained by the author(s), with first publication rights granted to the journal.

This is an open-access article distributed under the terms and conditions of the Creative Commons Attribution license (http://creativecommons.org/licenses/by/3.0/). 